\title{
Review of: "Dietary supplementation of alpha-lipoic acid mitigates the negative effects of heat stress in broilers"
}

\author{
Muqader Shah ${ }^{1}$ \\ 1 North West Frontier Province Agricultural University
}

Potential competing interests: The author(s) declared that no potential competing interests exist.

Dear Marinello,

I am thankful to you for considering me as a reviewer of the research article titled "Dietary

supplementation of alpha-lipoic acid mitigates the negative effects of heat stress in broilers". I have keenly reviewed the article and reached to the conclusion that the authors has done worked hard for designing this novel research project and manuscript writing with great skill. The manuscript has been written very concisely free of errors and understandable way. It is greatness of the journal for publishing such article. As far as article is concerned I am totally satisfied about the research article.

Regards 